Published in Computers in human behavior, August 2016, vol. 61, pp. 227-232 which should be cited to refer to this work

\title{
THE IMPACT OF ONLINE REAL-TIME INTERACTIVITY ON PATRONAGE INTENTION: THE USE OF AVATARS
}

\begin{abstract}
The objective of this paper is to examine the impact of online real-time interactivity on the desire of users to visit and to purchase products/services from the company in the future. Online real-time interactivity has been increased by the use of avatars. We also investigated the antecedents of online real-time interactivity by focusing on trust, emotional appeal, and social presence. As far as the methodology is concerned, we designated companies using avatars on their websites. We asked respondents to visit these websites and then fill in our questionnaire. We received 945 questionnaires back. As we had several latent variables, we used partial least squares (PLS), a variance-based structural equation modeling method. The results show that online real-time interactivity significantly increases the patronage intention. The results also illustrate the impact of the degree of trust and the emotional appeal on user's perception about the online real-time interactivity. Nevertheless, the impact of the emotional appeal is less relevant compared to the degree of trust. Moreover, the degree of trust in the information found on the website explains user's emotional appeal during the conversation. Finally, avatar's social presence has a significant impact on trust and emotional appeal. Our results have immediate and direct implications for avatars' developers and companies who want to invest in improving the real-time interactivity of their website.
\end{abstract}

Keywords Avatar, Website humanization, Social presence, Trust, Emotional appeal, Online real-time interactivity 


\section{THE IMPACT OF ONLINE REAL-TIME INTERACTIVITY ON PATRONAGE INTENTION: THE USE OF AVATARS}

\section{INTRODUCTION}

Websites are the virtual personality of a company and they are evolving in an environment that responds to a variety of activities, including entertainment, exploration, communication, and learning (Huang, 2003). They can bring new customers to your business, strengthen current relationships or, in the worst case, frustrate and turn away potential customers. One of the main reasons for customer dissatisfaction on the websites is the lack of interaction and humanity. A humanized approach would incorporate various human-centric elements, such as emotive textual descriptions, relevant pictures of people, appropriate audio and video clips, virtual communities, and virtual shopping agents (Head et al., 2003). By increasing the interactivity and humanizing the website through the use of an avatar, companies try to improve the customer online experience and in the same time to increase the firm online productivity. With advanced in the field of artificial intelligence and user interface, solutions can increase the online real-time interactivity.

Although many studies have focused on the impact of the avatar on user's online experience (e.g., Wang et al., 2007; Bridges and Florsheim, 2008; Keeling et al., 2010; Köhler et al., 2011; Childers et al., 2002; Gefen and Straub, 2004; Chung, 2005; Cyr et al., 2007; Holzwarth et al., 2006; Etemad-Sajadi and Ghachem, 2015), there is a lack of research about the effect of the avatar's real-time interactivity on the patronage intention (likelihood of visiting the company in the future) of current and potential customers. Therefore, this study makes the following academic contribution: We want to identify the impact of online realtime interactivity on patronage intention. In a research done on virtual worlds, Kohler et al. (2011) argued that when users have an involving experience, they participate more intensely. Prior research focused on the impact of this technology on the online purchase intention and 
less on the real patronage intention. Moreover, whereas prior research investigating virtual agents has integrated basic verbal and visual cues (Wang et al., 2007; Holzwarth et al., 2006), we want to investigate how the increase of online real-time interactivity through the use of avatar can influence the desire of potential users to visit and to purchase products/services from the company in the future. This study has major implications for avatars' developers and companies who want to invest in improving the real-time interactivity of their website. In parallel, we want to investigate the antecedents of online real-time interactivity by focusing on trust, emotional appeal, and social presence, which are key dimensions found in the literature (Keeling et al., 2010; Wang et al., 2007; Holzwarth et al., 2006; Etemad-Sajadi, 2014; Gefen and Straub, 2004).

\section{THEORETICAL BACKGROUND AND HYPOTHESES}

\subsection{Online avatars}

McGoldrick et al. (2008) summarized several terms found in the literature, such as “avatars” (Wood et al., 2005; Holzwarth et al., 2006), “virtual agents” (Abbattista et al., 2002), “embodied conversational agents” (ECAs) (Cassell et al., 2000), etc. They are animated characters that some companies use on their websites to mimic interaction with a human customer-service representative. These characters humanize the question-and-answer experience and simulate a real-time conversation (Wang et al.; 2007; Bridges and Florsheim, 2008); Keeling et al., 2010; Köhler et al., 2011; Etemad-Sajadi and Ghachem, 2015; Gefen and Straub, 2004). Despite very optimistic literatures, the virtual agents do not seem to keep always all their promises. According to Ben Mimoun et al. (2012), the reasons of that failure come from a lack of interactivity, intelligence, and autonomy. Corvello et al. (2011) also highlight the lack of interaction. Nevertheless, the majority of papers related to the topic confirmed the positive impact of virtual agents (Keeling et al., 2010; Wang et al., 2007; 
Holzwarth et al., 2006). Wang et al. (2007) found that hedonic and utilitarian values influence significantly the patronage intention of current and potential customers. They use an animated character with a computer voice in order to show the positive impact on users' perception. According to Holzwarth et al. (2006), the use of an avatar leads to a more positive attitude towards the company and a greater purchase intention. The design of the online avatar can also have an impact on users’ perception. Indeed, Mull et al. (2015) focused on different types of 3D animated avatars as salespeople (human, fantasy, animal and humanoid). They found that the human avatar was perceived as the most credible/attractive and was regarded as the highest in relation to intention to interact. Köhler et al. (2011) examined how customers adjust to complex service contexts (banking industry) by way of their agent-based online interactions. They focused on the content and style of agent-customer interactions. The content was separated to two aspects which are functional and social. As far as the style was concerned, it was defined as reactive versus proactive. Analyzing agent-customer conversations, Köhler et al. (2011) argued that a higher level of functional content and a proactive style enhance the user's knowledge about what is expected of him/her (role clarity), how to perform service tasks (self-efficacy), and how the website works (social acceptance). They also found that social content has a positive impact on newcomer adjustment. However, if the conversation is largely dominated by social content, users become dissatisfied with the lack of substance in the interaction. This can also be explained by the fact that in their research, they focused on banking industry which can be considered as a utilitarian industry. In a research done on restaurant industry, Etemad-Sajadi (2014) found that hedonic value of the virtual agent increases significantly the desire of potential clients to visit the restaurant. The impact of the hedonic value of the virtual agent is even more relevant than its utilitarian value. Hence, the nature of the company or the website plays an important role in the success of the avatar's implementation. 


\subsection{Online real-time interactivity}

According to Wang et al. (2007), interactivity is a social cue and can be explained by user's perception of connection. Establishing an online social connection is an important issue for companies. Zhang et al. (2014a) focused on the importance of commitment in the case of social virtual worlds. Compared to traditional shopping, in an online shopping environments customers do not have direct contacts with salespeople (Cyr et al., 2007). According to the same authors, these face-to-face interactions have therefore been replaced by a complex socio-technical system, often not well understood by users. Liu and Shrum (2002) specified the three dimensions of interactivity as i) active control (user's ability to voluntarily participate in and instrumentally influence a communication), ii) two-way communication (ability for reciprocal communication between the company and the user), and iii) synchronicity (degree to which users' input into a communication and the response they receive from the communication are simultaneous). This third dimension can be considered as the "real-time" interactivity. Steuer (1992) focused on the real-time dimension and defined interactivity as "the extent to which users can participate in modifying the form and content of a mediated environment in real-time”. His definition is based on a telepresence view of mediated communication and focused on properties of the mediated environment and the relationships of individuals to that environment. According to Kohler et al. (2011), when participants experience an online inspiring, involving and fun co-creation experience, they participate more intensely. Wang et al. (2007) found that the presence of the avatar can influence the patronage intention. According to Holzwarth et al. (2006), the use of an avatar leads to a more positive attitude towards the company and a greater purchase intention. Van Noort et al. (2012) argued that a higher level of website interactivity increases website visitors' online flow experience, which subsequently leads to positive outcomes of concern to marketers, such as favorable attitudes toward the website and the brand, increased number of 
product-relevant thoughts, and favorable behavioral intentions. In our context with the use of avatars and based on the literature above, we want to focus on the relationship between online real-time interactivity and patronage intention. Hence, we propose the following hypothesis:

H1. The online real-time interactivity will positively influence user's patronage intention.

\subsection{Trust}

Trust is a key element of success in the online environment (Gefen and Straub, 2003; Corritore et al., 2003). According to the literature, the facets of trust are reliability, ability, integrity, benevolence, and honesty (Giffin, 1967; Kumar, 1996; Geffen and Straub, 2004). Having trust in a website is primordial for increasing interaction (Gefen and Straub, 2003; Kim, 2012). Therefore, the degree of trust in the information found on the website and delivered by the avatar can potentially impact user's desire for interacting online. In parallel, trust can be positively related to user's enjoyment and emotional appeal (Hassanein and Head, 2004). Zhang et al. (2014c) also showed the relationship between the cognitive trust (beliefs) and the emotional feelings. Hence, we propose the following hypotheses:

H2. The degree of trust will positively influence user's desire for online real-time interactions.

H3. The degree of trust will positively influence user's emotional appeal.

\subsection{Emotional appeal}

Emotional appeal focuses on fun, playfulness, and emotional worth (Babin et al., 1994). In an online context, the emotional appeal is the emotional effect of using the website and the intensity of the involvement (Barnes and Vidgen, 2001; Loiacono et al., 2007). The emotional worth can increase user's desire for more interactions (Babin et al., 1994). Wang 
and Fodness (2010) also focused on the different roles of avatars and the users' emotional responses. Therefore, we propose the following hypothesis:

H4. The emotional appeal will positively influence user's desire for online real-time interactions.

\subsection{Avatar's social presence}

Social presence is described as the perception that there is personal, sociable, and sensitive human contact (Gefen and Straub, 2004). The definition is very close to telepresence which is defined as "the psychological state of 'being there' in a computer-mediated environment, augmented by focused attention. It is characterized by cognitive and sensory arousal, control, and immersion” (see Mollen and Wilson, 2010, pp. 921). Several authors identified that the perception of social presence can affect user trust in information given on a website (Sung and Mayer, 2012; Gefen and Straub, 2004; Hassanein and Head, 2007; Hess et al., 2008). According to them, the inclusion of social cues on a website facilitates the building of online trust. Steinbrück et al. (2002) also found that social presence through the use of an avatar increases online trust. In the same time, as the avatar can reduce the social distance, one can suppose that the increase of online socialization can positively impact the pleasure for user to communicate with the avatar and to navigate on the website. Indeed, several authors (e.g., Heeter, 1995; Hassanein and Head, 2007) found that users enjoyed the experience more when they felt a strong social presence. Wang and Fodness (2010) also suggested that a consumer's emotional response will be more positive on a website with a highly likeable avatar. Therefore, we propose the following hypotheses:

H5. The social presence of the avatar will positively influence user's trust on the website.

H6. The social presence of the avatar will positively influence user's emotional appeal. 
Figure 1 depicts our research model. The items will be explained below. In this research, we focused on the direct relationship between online real-time interactivity and patronage intention. Even, if the three other variables (trust, emotional appeal, and social presence) can directly impact the patronage intention, we wanted to identify the intermediary role of the online real-time interactivity. In this research, trust, emotional appeal, and social presence are considered as prerequisite for increasing the online real-time interactivity.

Figure 1: Research model

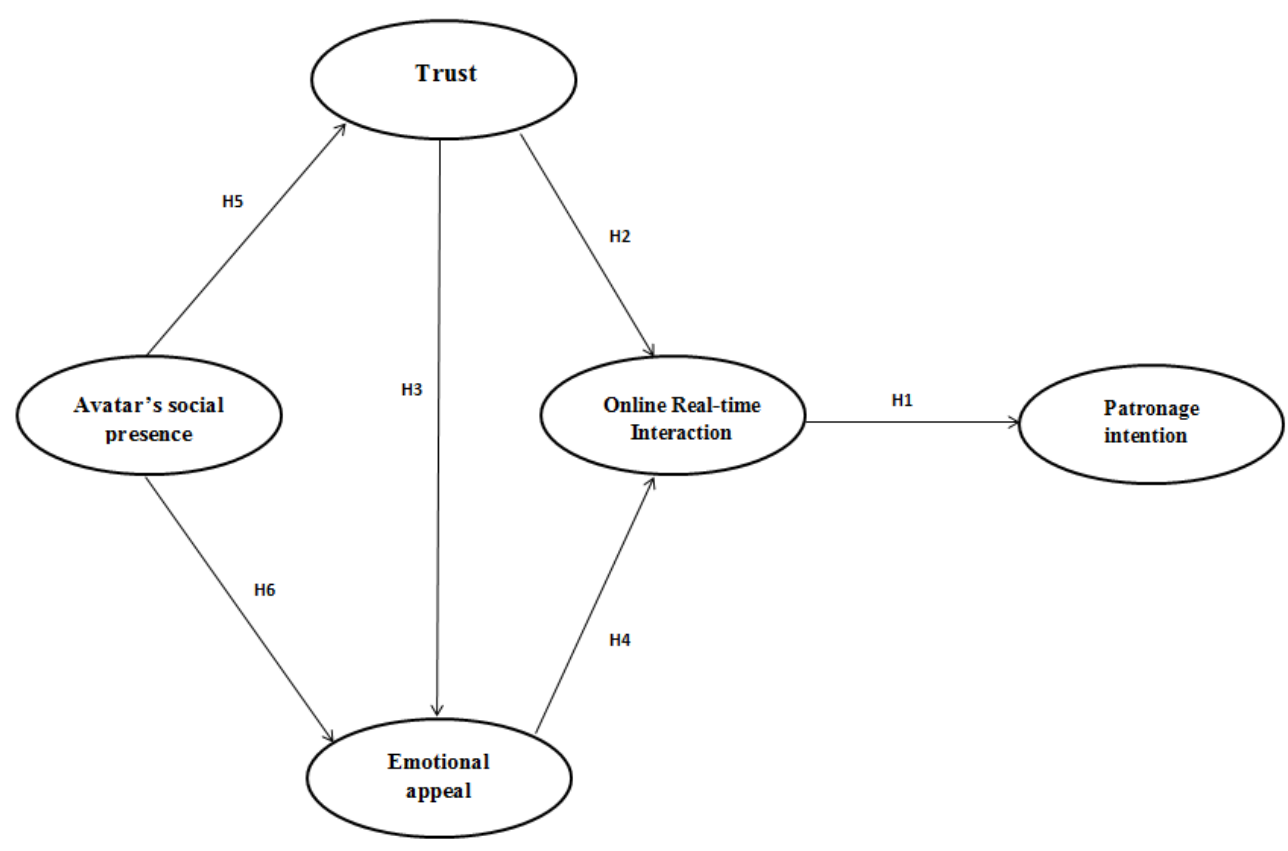

\section{METHODOLOGY}

\subsection{Measures}

Responses to the items presented below (which were taken from extant measures) were used to create this current study's measures and to assess this study's hypothesized structural model. Response options for each item ranged from 1 (strongly disagree) to 7 (strongly agree). 
Social presence was assessed with items adapted from Gefen and Straub (2003). Trust was assessed with items adapted from Gefen and Straub (2003), Gefen and Straub (2004), and Cyr et al. (2005). Emotional appeal was assessed with items adapted from Agarwal and Karahanna (2000), Hassanein and Head (2007), and Heijden (2003). Online real-time interactivity was assessed with items adapted from Liu (2003) and Wu (1999). Finally, patronage intention was assessed with items adapted from Hellier et al. (2003). Table 1 summarizes our items.

\section{Table 1: Questionnaire items}

\begin{tabular}{|c|c|}
\hline Constructs & Items \\
\hline AVATAR'S SOCIAL & The virtual agent looks human. \\
\hline \multirow[t]{2}{*}{ PRESENCE } & The virtual agent looks empathic. \\
\hline & The virtual agent looks clever. \\
\hline \multirow[t]{4}{*}{ TRUST } & I trust the reliability of information found on this website. \\
\hline & I trust this website to keep personal information secure. \\
\hline & The virtual agent looks trustworthy. \\
\hline & I trust the information given by the virtual agent. \\
\hline \multirow[t]{4}{*}{ EMOTIONAL APPEAL } & The design of the website is visually pleasing. \\
\hline & I feel cheerful due to the friendliness of the website. \\
\hline & The interaction with the virtual agent is pleasant. \\
\hline & The interaction with the virtual agent is funny. \\
\hline ONLINE REAL-TIME & The website allows me to interact with it in order to receive information. \\
\hline INTERACTIVITY & The website has interactive features to meet my needs. \\
\hline
\end{tabular}


having to call the company.

The virtual agent allows to easily find the desired information without having to write an email to the company.

The interaction with the virtual agent is efficient.

PATRONAGE INTENTION

Visiting this website increases my desire to make business with the company.

The website gives me the impression that making business with this company will be positive.

\subsection{Sampling and data collection procedures}

We launched several on-line surveys in parallel based on the following service companies using an avatar: Continental Airline, Alaska, Vueling, On the beach, Hispeed, Amtrak, Ikea, MGS. These companies operate in the following industries: airline carrier, online travel agency, telecommunications, rail transport, furniture retailing and health insurance. We selected the companies using relatively similar avatars (2D animated character). We used Amazon Mechanical Turk (94.9\%) and the clients of firms selected (5.1\%) for answering to our questionnaire. Overall, we received 945 questionnaires back. The sex of respondents was divided with 561 male and 384 female. The age of respondents is between 18 and 79, with an average age of 33.6. We asked respondents to take between 5 and 10 minutes to visit the website and interact with the virtual agent. Then, they had to answer our questionnaire.

\subsection{Data analysis method}

Structural equation modeling (SEM) was adopted to test the hypotheses due to the fact that the model contains several latent variables. SmartPLS 2.0 was used for the analysis. We employed a bootstrapping method (200 sub-samples) to test the significant level of 
regression path coefficients (Hair et al., 2011). We used the blindfolding approach (crossvalidated communality and redundancy). The cross-validated communality index measures the quality of the measurement model of each block. The quality of each structural equation is measured by the cv-redundancy index (i.e. Stone-Geisser $\mathrm{Q}^{2}$ ). The Stone-Geisser $\mathrm{Q}^{2}$ for online real-time interactivity and patronage intention is respectively 0.44 and 0.35 . $\mathrm{Q}^{2}$ measures the extent to which observed values are reconstructed by the model and its parameter estimates (Chin, 1998). The technique represents a synthesis of function fitting and cross-validation (Henseler et al., 2009). If it is negative, the model has no predictive relevance; values around 0.15 indicate a medium predictive relevance and around 0.35 a large predictive relevance (Henseler et al., 2009; Hair et al., 2012). In this model, the independent variables are therefore good predictors for online real-time interactivity and patronage intention.

\section{RESULTS}

\subsection{Reliability and validity of measures}

Table 2 shows that all latent variables have a composite reliability higher than 0.75 , confirming that the scale reliabilities have adequate and stable measurement properties. Convergent and discriminant validity are components of a larger measurement concept known as construct validity (Straub et al., 2004). Convergent validity is shown when each measurement item is strongly correlated with its construct. It is usually satisfied by retaining variables whose loadings are high, indicating that they share sufficient variance with their related construct. Discriminant validity is satisfied when each measurement item is weakly correlated with all other constructs except with the one to which it is theoretically associated (Gefen and Straub, 2005). With PLS, convergent and discriminant validities are confirmed if each construct AVE is larger than its correlation with other constructs. Moreover each item should load more highly on its assigned construct than on the other constructs (Gefen et al., 
2000; Straub et al., 2004). Table 2 shows the intercorrelation of the research constructs. The diagonal of this matrix represents the square root of the average variance extracted. For adequate discriminant validity, the diagonal elements should be significantly larger than the correlation of the specific construct with any of the other constructs and should be at least 0.5 (Fornell and Larcker, 1981). In our case, one can claim that discriminant validity is confirmed and sufficient to support the model.

Table 2: Reliability and discriminant validity

\begin{tabular}{|c|c|c|c|c|c|c|}
\hline Constructs & $\begin{array}{l}\text { Composite } \\
\text { reliability }\end{array}$ & 1 & 2 & 3 & 4 & 5 \\
\hline 1. Avatar's social presence & .91 & $.88^{\mathrm{a}}$ & & & & \\
\hline 2. Trust & .85 & $.61^{* *}$ & .77 & & & \\
\hline 3. Emotional appeal & .78 & $.51^{* *}$ & $.61^{* *}$ & .69 & & \\
\hline 4. Online real-time interactivity & .93 & $.49 * *$ & $.76 * *$ & $.60 * *$ & .85 & \\
\hline 5. Patronage intention & .93 & $.40^{* *}$ & $.65^{* *}$ & $.68^{* *}$ & $.64^{* *}$ & .93 \\
\hline $\begin{array}{l}\text { Correlation is significant at the } \\
\text { Diagonal: (Average Variance E }\end{array}$ & $\begin{array}{l}\text { level. } \\
\text { ted })^{1 / 2}=(\Sigma \lambda\end{array}$ & & & & & \\
\hline
\end{tabular}

\subsection{Results and discussion}

Figure 2 presents the results of the PLS analysis and the values of different path coefficients. One can observe that the online real-time interactivity significantly increases the patronage intention $(\gamma=0.647)$. Indeed, $41.8 \%$ of variance of patronage intention is explained by the online real-time interactivity. Hence $H 1$ is accepted. Prior research focused on the impact of this technology on the online purchase intention and less on the real patronage intention. This result is relevant as it shows that on-line real-time interaction increases the desire of users to visit and to purchase products/services from the company in the future. Companies can increase the patronage intention of their clients or potential clients by increasing the real-time interaction on their website.

Trust in the information found on the website explains user's desire for online realtime interaction $(\gamma=0.627)$ and user's emotional appeal $(\gamma=0.476)$. Hence $H 2$ and $H 3$ are 
both confirmed. These results confirm the important role of trust and firms should continuously control if all information given by their online avatar are up to date. It will significantly impact users' pleasure and desire to interact with the company through the online channel.

As far as the impact of the emotional appeal on online real-time interactivity is concerned, one can claim that it is significant $(\gamma=0.222)$. Hence, even if $H 4$ is less relevant compared to H2, it is also confirmed. Indeed, comparing the two variables impacting user's perception of online real-time interaction, we observe that the influence of trust is higher than the emotional appeal (respectively $\gamma=0.627$ and $\gamma=0.222$ ). Nevertheless, the pleasure and the emotional appeal are important issues and should be considered in the implementation of the avatar.

Finally, the avatar's social presence has a significant impact on trust $(\gamma=0.630)$. The humanization of the website through the use of avatar increases trust in the information found on the website. It explains $39.7 \%$ of variance of trust. In parallel, the avatar's social presence also impacts user's emotional appeal $(\gamma=0.219)$ even if the coefficient is less important compared to trust. Hence, the H5 and H6 are also confirmed. These results highlight the importance of human and social cues of the avatar. It increases the degree of trust in information found online and the pleasure of visiting the website. 
Figure 2: Results of the PLS analysis

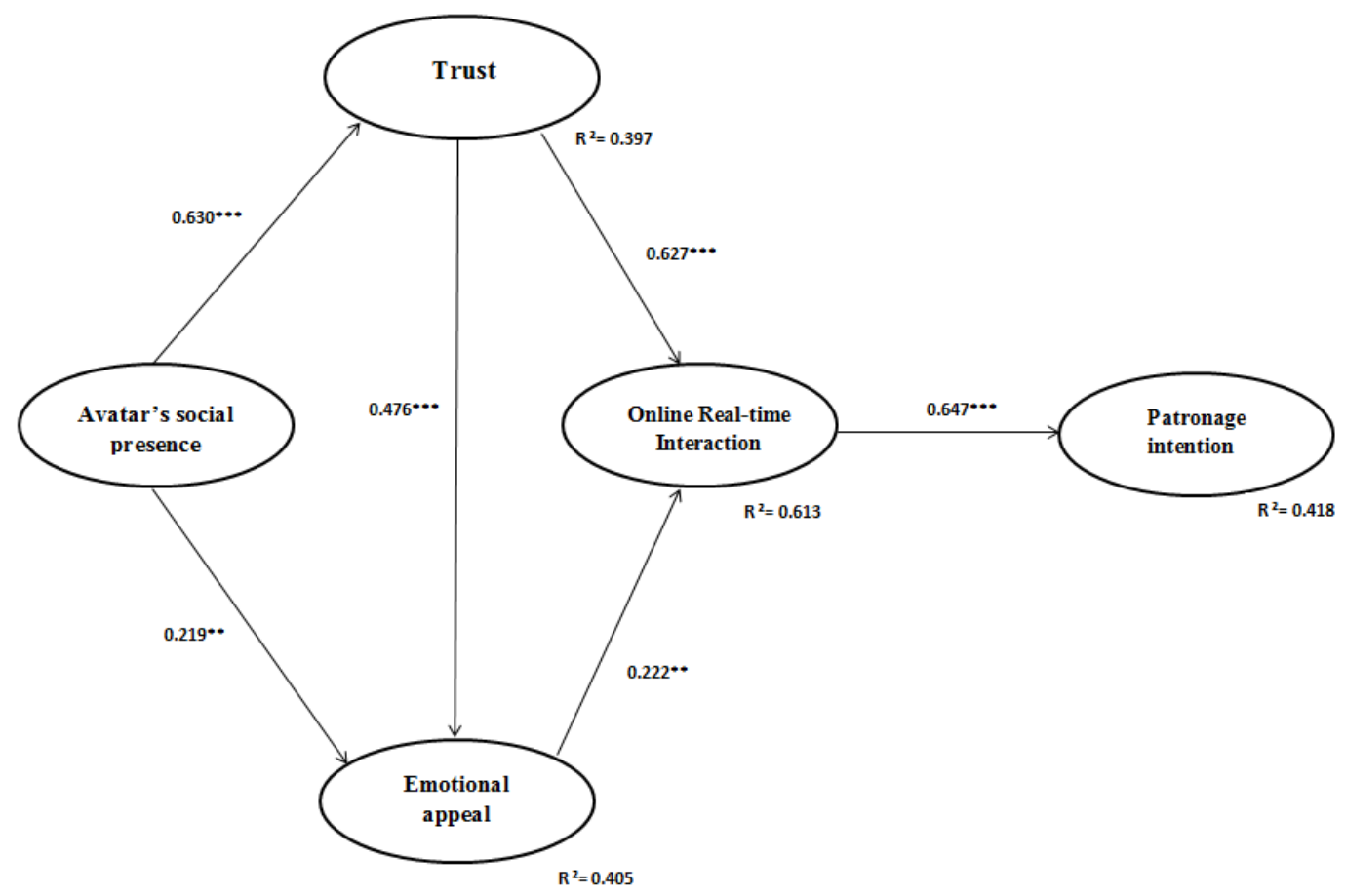

Notes:

** Significant at 0.01 level

*** Significant at 0.001 level

\section{CONCLUSION}

Virtual worlds are receiving increased global attention in a wide range of areas (Zhang et al. 2014b). Companies often use their websites as an important tool to communicate the goods and services they provide. Additionally, certain companies may want to convey ascertain important values and convey services that are neither at the core of their business, nor explicitly offered to clients. It may be something as simple as wanting to express the level of quality clients can expect from that company, or something such as reinforcing positive company values. Subsequently, this research shows that humanizing websites through the use of avatars can offer solutions to achieve this goal and contribute to businesses significantly by increasing the online real-time interactivity. Indeed, our findings show that online real-time interactivity significantly increases the patronage intention. The results also illustrate the 
impact of trust and emotional appeal on user's perception about the online real-time interactivity. The relationship between trust and online real-time interactivity is higher than the relationship between emotional appeal and online real-time interactivity. Moreover, the degree of trust in the information found on the website explains user's pleasure during the conversation. We also found that avatar's social presence has a significant impact on trust and emotional appeal. This provides the possibility for a company to develop a certain ‘relationship’ with site visitors. For example, if users are left with positive experiences after visiting the website, and these emotions are retained, this could perpetuate a positive word-ofmouth effect. These results have immediate and direct implications for avatars' developers and companies who want to invest in improving the real-time interactivity of their website.

In the future, it can be interesting to analyze the direct impact of trust, social presence, and emotional appeal on patronage intention. Indeed, in this paper we wanted to focus on the direct relationship between online real-time interactivity and patronage intention. Even, if the three other variables (trust, emotional appeal, and social presence) could directly impact the patronage intention, we wanted to identify the intermediary and the significant role of the online real-time interactivity.

One limitation of this research paper stems from the profile of respondents. Indeed, the average age is 33.6, which could create a bias in our findings. A second limitation comes from the fact that websites have been selected with an integrated avatar. Even if these avatars were relatively similar, they did not have the exact same profile. Nevertheless, the goal of our research was not to measure the performance of the avatar, but more its impact on users' perception about the degree of interactivity, trust, emotional appeal, and social presence. Moreover, in order to generalize our findings, we selected eight different websites with eight different avatars. Therefore, this limitation can be considered as controlled. We hope that this current study’s findings foster future research on the humanization of websites. 


\section{REFERENCES}

- Abbattista, F., Anderson, V., Anderson, H. H. K., Lops, P. and Semeraro, G. (2002). Evaluating virtual agents for e-commerce. First International Joint Conference on AAMAS, Bologna, Italy.

- Agarwal, R., \& Karahanna, E. (2000). Time flies when you're having fun: Cognitive absorption and beliefs about information technology usage. MIS quarterly, 665-694.

- Babin, B. J., Darden, W. R., \& Griffin, M. (1994). Work and/or fun: measuring hedonic and utilitarian shopping value. Journal of Consumer Research, 644-656.

- Barnes, S.J. and Vidgen, R. (2001). An evaluation of cyber-bookshops: the WebQual method. International Journal of Electronic Commerce, 6(1), 11-30.

- Ben Mimoun, M. S., Poncin, I., \& Garnier, M. (2012). Case study-Embodied virtual agents: An analysis on reasons for failure, Journal of Retailing and Consumer services, 19(6), 605-612.

- Bridges, E., \& Florsheim, R. (2008). Hedonic and utilitarian shopping goals: the online experience. Journal of Business Research, 61(4), 309-314.

- Cassell, J., Sullivan, J., Prevost, S. and Churchill, E. (2000). Embodied conversational agents. Cambridge, MA: MIT Press.

- Childers, T. L., Carr, C. L., Peck, J., \& Carson, S. (2002). Hedonic and utilitarian motivations for online retail shopping behavior. Journal of Retailing, 77(4), 511-535.

- Chin, W. W. (1998). The partial least squares approach to structural equation modeling. Modern Methods for Business Research, 295(2), 295-336.

- Chung, D. (2005). Something for nothing: understanding purchasing behaviors in social virtual environments. Cyberpsychology \& Behavior, 8(6), 538-554.

- Corritore, C. L., Kracher, B., \& Wiedenbeck, S. (2003). On-line trust: concepts, evolving themes, a model. International Journal of Human-Computer Studies, 58(6), 737-758.

- Corvello, V., Pantano, E., \& Tavernise, A. (2011). The Design of an Advanced Virtual Shopping Assistant for Improving Consumer Experience. Advanced Technologies Management for Retailing, Hershey, 70-86.

- Cyr, D., Hassanein, K., Head, M., \& Ivanov, A. (2007). The role of social presence in establishing loyalty in e-service environments. Interacting with Computers, 19(1), 43-56.

- Cyr, D., Bonanni, C., Bowes, J., \& Ilsever, J. (2005). Beyond trust: Web site design preferences across cultures. Journal of Global Information Management, 13(4), 24-52. 
- Etemad-Sajadi, R. (2014). The influence of a virtual agent on web-users' desire to visit the company: The case of restaurant's web site. International Journal of Quality \& Reliability Management, 31(4), 419-434.

- Etemad-Sajadi, R., \& Ghachem, L. (2015). The impact of hedonic and utilitarian value of online avatars on e-service quality. Computers in Human Behavior, 52, 81-86.

- Fornell, C., \& Larcker, D. F. (1981). Evaluating structural equation models with unobservable variables and measurement error. Journal of Marketing Research, 39-50.

- Gefen, D., Straub, D., \& Boudreau, M. C. (2000). Structural equation modeling and regression: Guidelines for research practice. Communications of the association for information systems, 4(1), 1-77.

- Gefen, D., \& Straub, D. W. (2003). Managing user trust in B2C e-services. E-service Journal, 2(2), 7-24.

- Gefen, D., \& Straub, D. W. (2004). Consumer trust in B2C e-commerce and the importance of social presence: experiments in e-products and e-services. Omega, 32(6), 407-424.

- Gefen, D., \& Straub, D. (2005). A practical guide to factorial validity using PLS-Graph: Tutorial and annotated example. Communications of the Association for Information Systems, 16(1), 91-109.

- Giffin, K. (1967). The contribution of studies of source credibility to a theory of interpersonal trust in the communication process. Psychological bulletin, 68(2), 104-120.

- Hair, J. F., Ringle, C. M., \& Sarstedt, M. (2011). PLS-SEM: Indeed a silver bullet. The Journal of Marketing Theory and Practice, 19(2), 139-152.

- Hair, J. F., Sarstedt, M., Ringle, C. M., \& Mena, J. A. (2012). An assessment of the use of partial least squares structural equation modeling in marketing research. Journal of the Academy of Marketing Science, 40(3), 414-433.

- Hassanein, K., \& Head, M. (2007). Manipulating perceived social presence through the web interface and its impact on attitude towards online shopping. International Journal of Human-Computer Studies, 65(8), 689-708.

- Head, M., Hassanein, K., \& Cho, E. (2003). Establishing e-trust through humanized website design. In Proc. 16th Bled eCommerce Conf (pp. 9-11).

- Hassanein, K., \& Head, M. (2004). The influence of product type on online trust. In Proc. 17th Bled eCommerce Conf . 
- Heeter, C. (1995). Communication research on consumer VR. Communication in the age of virtual reality, 191-218.

- Heijden, H.v.d. (2003). Factors influencing the usage of websites: the case of a generic portal in The Netherlands. Information \& management, 40(6), 541-549.

- Hellier, P. K., Geursen, G. M., Carr, R. A., \& Rickard, J. A. (2003). Customer repurchase intention: A general structural equation model. European journal of marketing, 37(11/12), 1762-1800.

- Henseler, J., Ringle, C. M., \& Sinkovics, R. R. (2009). The use of partial least squares path modeling in international marketing. Advances in International Marketing, 20, 277319.

- Hess, T. J., Fuller, M., \& Campbell, D. E. (2009). Designing interfaces with social presence: Using vividness and extraversion to create social recommendation agents. Journal of the Association for Information Systems, 10(12), 889-919.

- Holzwarth, M., Janiszewski, C., \& Neumann, M. M. (2006). The influence of avatars on online consumer shopping behavior. Journal of Marketing, 70(4), 19-36.

- Huang, M. H. (2003). Designing website attributes to induce experiential encounters. Computers in Human Behavior, 19(4), 425-442.

- Keeling, K., McGoldrick, P., \& Beatty, S. (2010). Avatars as salespeople: Communication style, trust, and intentions. Journal of Business Research, 63(8), 793800 .

- Kim, J. B. (2012). An empirical study on consumer first purchase intention in online shopping: integrating initial trust and TAM. Electronic Commerce Research, 12(2), 125150.

- Kohler, T., Fueller, J., Stieger, D., \& Matzler, K. (2011). Avatar-based innovation: Consequences of the virtual co-creation experience. Computers in Human Behavior, 27(1), 160-168.

- Köhler, C. F., Rohm, A. J., de Ruyter, K., \& Wetzels, M. (2011). Return on interactivity: the impact of online agents on newcomer adjustment. Journal of Marketing, 75(2), 93108.

- Kumar, N. (1996). The power of trust in manufacturer-retailer relationships. Harvard business review, 74(6), 92-106.

- Liu, Y., \& Shrum, L. J. (2002). What is interactivity and is it always such a good thing? Implications of definition, person, and situation for the influence of interactivity on advertising effectiveness. Journal of advertising, 31(4), 53-64. 
- Liu, Y. (2003). Developing a scale to measure the interactivity of websites.Journal of advertising research, 43(02), 207-216.

- Loiacono, E. T., Watson, R. T., \& Goodhue, D. L. (2007). WebQual: an instrument for consumer evaluation of web sites. International Journal of Electronic Commerce, 11(3), 51-87.

- McGoldrick, P. J., Keeling, K. A., \& Beatty, S. F. (2008). A typology of roles for avatars in online retailing. Journal of Marketing Management, 24(3-4), 433-461.

- Mollen, A., \& Wilson, H. (2010). Engagement, telepresence and interactivity in online consumer experience: Reconciling scholastic and managerial perspectives. Journal of business research, 63(9), 919-925.

- Mull, I., Wyss, J., Moon, E., \& Lee, S. E. (2015). An exploratory study of using 3D avatars as online salespeople: The effect of avatar type on credibility, homophily, attractiveness and intention to interact. Journal of Fashion Marketing and Management, 19(2), 154-168.

- Steinbrück, U., Schaumburg, H., Duda, S., Krüger, T. (2002). A picture says more than a thousand words - photographs as trust builders in e-commerce websites. Proceedings of CHI, 748-749.

- Steuer, J., Biocca, F., \& Levy, M. R. (1995). Defining virtual reality: Dimensions determining telepresence. Communication in the age of virtual reality, 33-56.

- Straub, D., Boudreau, M.C. and Gefen, D. (2004). Validation guidelines for IS positivist research. Communications of the Association for Information Systems, 14, 380-426.

- Sung, E., \& Mayer, R. E. (2012). Five facets of social presence in online distance education. Computers in Human Behavior, 28(5), 1738-1747.

- Van Noort, G., Voorveld, H. A., \& van Reijmersdal, E. A. (2012). Interactivity in brand web sites: cognitive, affective, and behavioral responses explained by consumers' online flow experience. Journal of Interactive Marketing, 26(4), 223-234.

- Wang, L. C., Baker, J., Wagner, J. A., \& Wakefield, K. (2007). Can a retail web site be social?. Journal of Marketing, 71(3), 143-157.

- Wang, L. C., \& Fodness, D. (2010). Can avatars enhance consumer trust and emotion in online retail sales?. International Journal of Electronic Marketing and Retailing, 3(4), 341-362.

- Wood, N. T., Solomon, M. R., \& Englis, B. G. (2005). Personalisation of online avatars: is the messenger as important as the message?. International Journal of Internet Marketing and Advertising, 2(1-2), 143-161. 
- Wu, G. (1999). Perceived interactivity and attitude toward web sites. Proceedings of the conference - American Academy of Advertising (pp. 254-262). American Academy of Advertising.

- Zhang, X., De Pablos, P. O., Wang, X., Wang, W., Sun, Y., \& She, J. (2014a). Understanding the users' continuous adoption of 3D social virtual world in China: A comparative case study. Computers in Human Behavior, 35, 578-585.

- Zhang, J. X., Zhang, H., De Pablos, P.O., \& Sun, Y. (2014b). Challenges and Foresights of Global Virtual Worlds Markets. Journal of Global Information Technology Management, 17(2), 69-73.

- Zhang, K. Z., Cheung, C. M., \& Lee, M. K. (2014c). Examining the moderating effect of inconsistent reviews and its gender differences on consumers' online shopping decision. International Journal of Information Management, 34(2), 89-98. 